\title{
Managing Cognitive and Affective Trust in the Conceptual R\&D Organization
}

Diane H. Sonnenwald

\author{
Göteborg University and University College of Borås
}

\section{INTRODUCTION}

In today's distributed, knowledge-based and competitive economy there are many challenges facing scientific research and development (R\&D). To address these challenges, innovative approaches to management of geographically distributed and multi-institutional, or interorganizational, $\mathrm{R} \& \mathrm{D}$ are emerging. One approach is the conceptual organization (Sonnenwald, 2002).

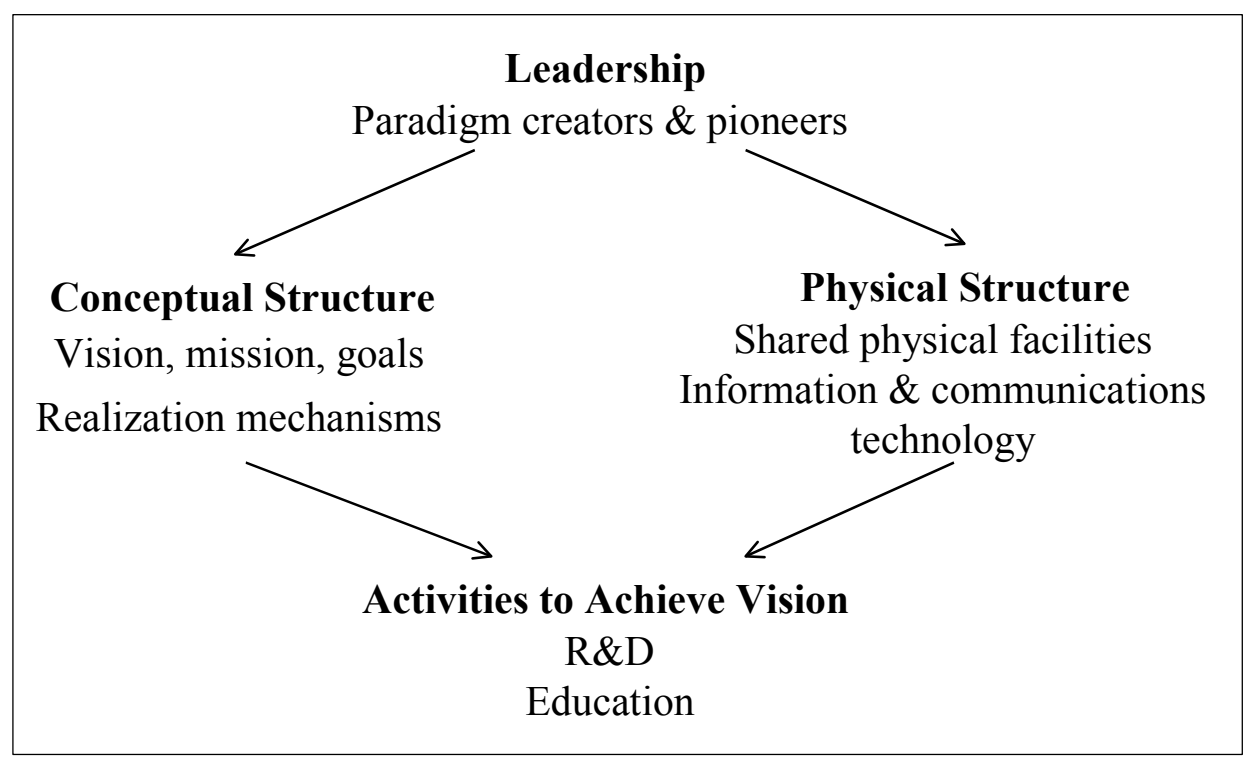

Figure 1. Components of a conceptual organization

A conceptual organization (Figure 1) is founded based on a long-term vision that addresses large complex and challenging problems of national and global importance. Its purpose is to work towards this vision, quickly and effectively contributing to relevant dynamic knowledge bases and meeting diverse stakeholder needs with minimum capitalization and start-up costs. To achieve this, it has an explicit conceptual organizational structure in addition to a physical structure, both of which are interwoven across other external organizational and multiple physical locations and structures. A conceptual organization is led by paradigm creators and pioneers, and has few employees in the traditional sense. Rather it engages scientists through the appeal of its vision and implementation of socio-technical infrastructures that encourage and

Sonnenwald, D.H. (2003). Managing cognitive and affective trust in the conceptual R\&D organization. In M. Iivonen and M. Huotari (Eds.), Trust in Knowledge Management and Systems in Organizations (pp. 82-106). Hershey, PA: Idea Publishing. 
facilitate activities to achieve that vision. Its power is primarily integrative in nature, and collaboration is a primary mechanism used to achieve its organizational goals.

This chapter explores the management of cognitive and affective trust and distrust within the conceptual organization. Cognitive trust focuses on judgments of competence and reliability, and affective trust focuses on interpersonal bonds among individuals and institutions. Both cognitive and affective trust play an integral role in the conceptual organization because the organization relies on collaboration among individual members to achieve its goals and realize its vision. Collaboration is not possible without cognitive or affective trust. Yet cognitive and affective trust may be more difficult to manage in a conceptual organization because mechanisms, such as informal face-to-face interactions and observations, that typically are used in building and maintaining trust are not universally present. Previous research has shown that when organizations are geographically distributed, trust among members is negatively impacted (Handy, 1995; Rocco, Finholt, Hofer, \& Herbsleb, 2001; Jarvenpaa \& Leidner, 1995).

Data from a 2-year case study of a conceptual organization illuminates how the organization's infrastructure, in particular, its organizational structure and use of power and information and communications technology (I\&CT), impacts and relies on cognitive and affective trust. In addition, two examples illustrating everyday management of cognitive distrust in conjunction with affective trust, and affective distrust in conjunction with cognitive trust are examined.

These results are relevant to other organizations in the knowledge-based economy where an individual's competence and reliability are increasingly important, and in organizations where members are geographically distributed. In addition, the results help inform our theoretical understanding of cognitive and affective trust and distrust, and their impact on collaboration.

\section{THEORETICAL FRAMEWORK}

\section{Definitions of Trust and Distrust}

There are many definitions of trust arising from different disciplinary perspectives. When synthesizing these definitions, Rosseau, Sitkin, Burt and Camerer (1998) found that scholars fundamentally agree that trust is a "psychological state comprising the intention to accept vulnerability based upon positive expectations of the intentions or behavior of another" (p. 395). Trust involves risk, or the probability of loss, and interdependence, or reliance on others.

Distrust can be defined in opposite terms, i.e., as negative expectations of the intentions or behavior of another (Lewicki, McAllister, \& Bies, 1998; Sztompka, 1999). It involves a lack of risk and no dependence on others. Trust and distrust can exist simultaneously in individuals (Lewicki, et al, 1998). They can be conceptualized as a continuum with high trust to high distrust as endpoints; that is, a continuum from high trust to low trust to low distrust to high distrust.

\section{Evolution of Trust and Distrust}

Feelings of trust and distrust can change over time (Jones \& George, 1998; McKnight, Cummings, \& Chervany, 1998). These changes occur as a result of observation of and reflection on behavior (Whitener, Bridt, Korsgaard, \& Werner, 1998). That is, trust and distrust are not behaviors but psychological conditions that influence an individual's behavior. 


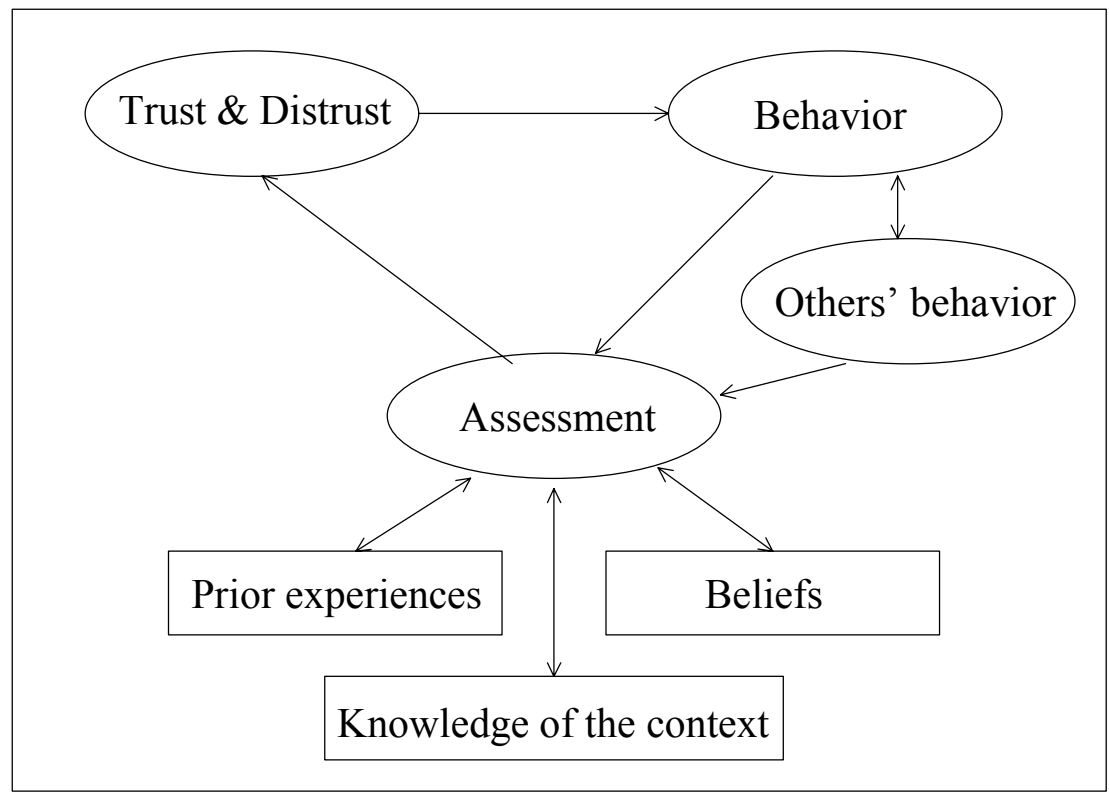

Figure 2. The evolutionary nature of trust and distrust

An individual's behavior influences others' behaviors, both of which may be assessed by the individual (Figure 2). This assessment is often based on prior experiences, knowledge of the context in which the behaviors occurred, and personal beliefs. The results of the assessment influences perceptions of trust and distrust, and future assessments (through the modification or re-enforcement of prior experiences, knowledge of the context and beliefs). Thus, trust and distrust shape one's own behavior and others' behavior whose assessment in turn shapes trust and distrust.

\section{Two Types of Trust and Distrust: Cognitive and Affective}

Two types of trust, cognitive and affective, have been identified as important in organizations (McAllister, 1995; Rocco, et al, 2001). Cognitive trust focuses on judgments of competence and reliability. Can a co-worker complete a task? Will the results be of sufficient quality? Will the task be completed on time? These are issues that comprise cognitive trust and distrust. The more strongly one believes the answers to these types of questions are affirmative, the stronger one's cognitive trust. The more strongly one believes the answers to these types of questions are negative, the stronger one's cognitive distrust.

Affective trust focuses on interpersonal bonds among individuals and institutions, including perceptions of colleagues' motivation, intentions, ethics and citizenship. Affective trust typically emerges from repeated interactions among individuals, and experiences of reciprocated interpersonal care and concern (Rosseau, et al, 1998). It is also referred to as emotional trust (Rocco, et al, 2001) and relational trust (Rosseau, et al, 1998). It can be "the grease that turns the wheel" (Sonnenwald, 1996). 


\section{Interaction among Cognitive and Affective Trust and Distrust}

Cognitive trust and distrust may exist in conjunction with affective trust and distrust (Table 1). High cognitive and affective trust typically yields tightly coupled collaboration in which tasks and ideas are openly shared and frequently shared. Scientists talk of friendship and of liking each other, when affective and cognitive trust is high. Risk and vulnerability caused by collaboration is perceived as low.

In comparison, high affective distrust and high cognitive distrust can be sufficient to dissuade individuals from collaborating at all. No friendship exists or develops, and individuals may proactively limit their interaction with others they cognitively and affectively distrust. Collaboration and interaction is perceived as a high risk and as a high degree of vulnerability.

Table 1. Relationships Among Cognitive and Interpersonal Trust and Distrust

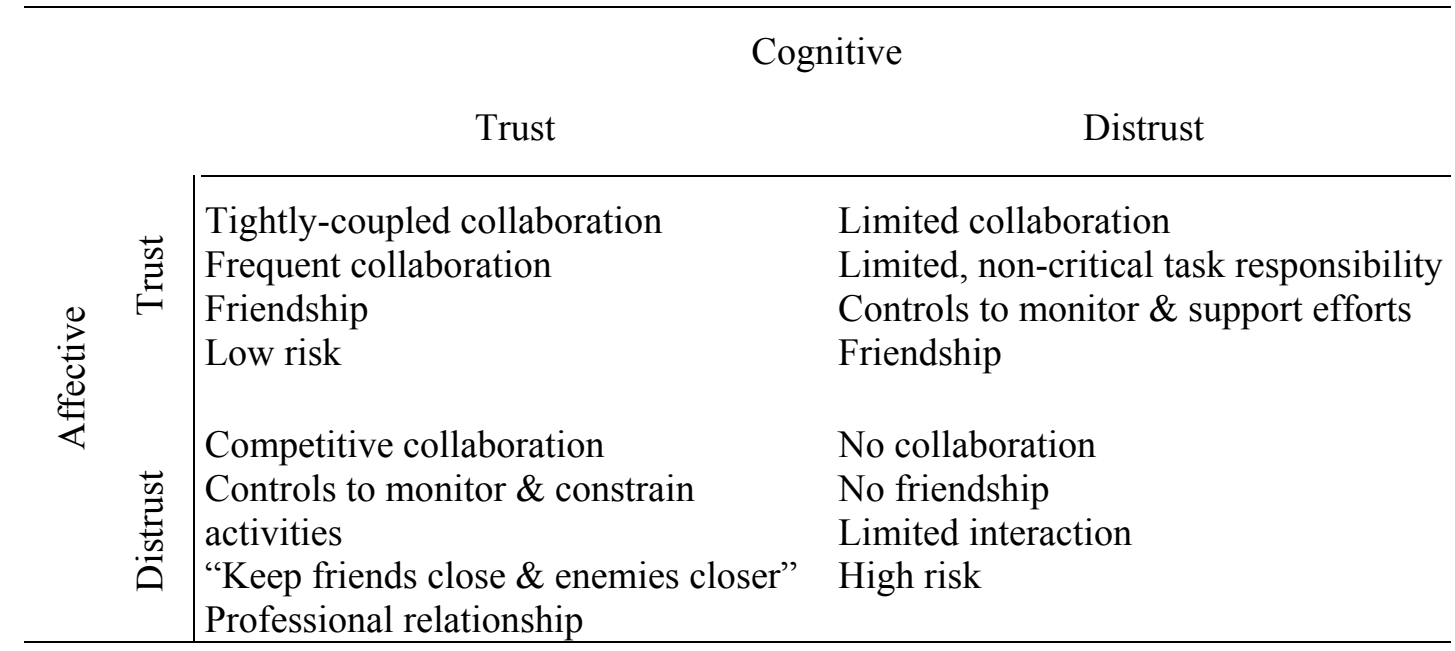

A trust-distrust match between cognitive and affective trust can yield problematic situations that require explicit management. Feelings of high cognitive distrust and high affective trust may serve to limit collaboration. Primarily non-critical or unimportant tasks will be given to individuals that are cognitively distrusted. However, friendship as a result of affective trust may exist (or emerge). Controls to monitor and support task completion efforts may be used. For example, mentoring and training may be employed to help a friend who is not cognitively trusted.

Feelings of high cognitive trust and high affective distrust can result in competitive collaboration. Controls to monitor and constrain task or work activities emerge to manage the affective distrust. The saying, "keep friends close and enemies closer," appears applicable in these types of situations. Professional relationships may exist (or emerge) but friendship and the perception that the collaboration or interaction is fun does not. 


\section{RESEARCH METHODLOGY}

This chapter emerged from an in-depth 2-year case study of an R\&D Center. The primary purpose of the case study was to investigate how social processes and information and communications technology (IC\&T) may facilitate and/or impede collaboration in research and development.

\section{Research Setting}

The case study took place at an R\&D Center in the USA. The R\&D Center was first funded late 1999, with a five-year $\$ 15$ million dollar commitment from a national funding agency with matching support from several participating universities, corporations and a non-profit foundation. Initially, the Center had approximately 30 faculty scientists, 82 students and postdoctoral fellows, and three full-time staff members. The faculty and students were located at four universities in the U.S. Membership has changed over the years, and at the time this chapter was written there were approximately 45 faculty scientists, 70 students and postdoctoral fellows and three full-time staff members physically located at five U.S. universities.

\section{Data Collection and Analysis}

This case study began during the beginning stages of the Center and continued for two years. During the proposal stage initial plans for the Center were developed and submitted to a national funding agency for review. Next, the funding agency organized an on-site review at which the proposed Center management team, invited university administrators, and corporate and private sponsors presented more detailed plans and motivation for the Center. Approximately six months later, the Center was approved and it officially began operating two months later. It had been in operation for two years at the time this chapter was written.

While conducting the case study, the author was a participant observer. As noted by Adler and Adler (1987), three levels of participant observation are possible: complete, active and peripheral. The author primarily assumed a complete membership role, switching to a peripheral membership role when activities focused on research outside her area of expertise. As a complete member, the author had functional, in addition to research, roles in the research setting. For example, the author served as the Center Coordinator of Social Science Research Efforts and a member of the Center management team. She actively participated in the management meetings, contributing to discussions and participating in decision-making. However, when the meetings and decision-making focused on research in natural science and engineering topics, topics not in the author's areas of expertise, she assumed the role of a peripheral participant observer. She observed the activity, taking notes and audio-recordings, and occasionally discussed events and outcomes with meeting participants but she did not actively participate in the discussions and decision-making. Seventy-three management team meetings were held during the two-year study, and the author observed and participated in these meetings. The author was periodically a peripheral member participant in center-wide weekly research meetings, generally observing discussions and only completely participating when discussions regarding collaboration and collaboration technology took place. Center members were made aware of the author's roles.

Observation data included transcribed audio-recordings of meetings, video-recordings of videoconferences, meeting and Center documentation and researcher notes. These data were analyzed using semantic content analysis (Robson, 2002), i.e., themes and meanings behind the observations and meeting transcripts were sought. General themes investigated include organizational structure and management practices and their impact (both positive and negative) 
on trust, the use of information and communications technology and its impact on trust, and breakdowns of trust. These themes were selected based on previous research that discusses the impact of management and technology on trust (e.g., Whitener, et. al., 1998; Rocco, et. al., 2001). Examples of these themes were identified and synthesized in topic memos. This was an iterative process, with all data analyzed multiple times, searching for additional data regarding these themes, synthesizing the data, and interpreting the meaning behind the data. The results are presented in the following sections.

Two sociometric surveys were also conducted to provide quantitative data regarding collaboration within the Center. The survey instruments listed each Center member and their university affiliation. Respondents were asked to specify who they currently worked, or interacted, with, and to briefly describe the focus of that work. Examples of foci listed are "cleaning and mass transfer study," "exchange ideas and collaborate on ... cleaning mechanisms," and "design of apparatus." The surveys were sent to all Center members approximately 12 and 24 months after the Center was established. Response rates for the two surveys were $68 \%$ and $73 \%$, respectively. The data were analyzed using sociometric techniques (Wasserman \& Faust, 1994) to investigate the number of collaborations among scientists and students, collaborations across universities and changes in collaborations over time.

\section{THE ROLE OF INFRASTRUCTURE IN MANAGING TRUST WITHIN THE CONCEPTUAL ORGANIZATION}

This section discusses how aspects of the conceptual organization are implemented and how the implementations appear to shape, and are shaped by, cognitive and affective trust within the organization.

\section{Organizational Structure and Membership Selection}

The organizational structure of the conceptual organization observed in this case study includes a director who sets the overall prioritization for the Center and is responsible for leading the strategic vision and planning process. In addition, the Director for this Center takes a lead in organizing the research as well as the dissemination of the research in real time by organizing the center-wide group meetings. As Director, this person also leads the interactions with the external stakeholder groups, such as the national funding agency, an external advisory board, affiliate university administrations and the media. In addition to these responsibilities, the Director teaches and conducts research at his local university.

This Center also has a Co-Director and a Deputy Director. The Co-Director is a close research collaborator to the Director and is essentially interchangeable with the Director in many functions. The Co-Director's primary responsibility is financial leadership and leadership in strategic planning. The Co-Director is also the leader of the external industrial affiliates group and conducts research. Outside the context of the Center, he directs a non-profit foundation.

The Deputy Director is a position created explicitly to help with the numerous administration requirements associated with the Center. The Deputy Director plays an organizational lead position for the strategic plan and its implementation and accountability. The Deputy Director is also responsible for leading the generation of the annual report and overall compliance with the cooperative agreement between the universities and the funding agency. In a supporting role, the Deputy Director also assists with the numerous outreach programs from the Center and represents the Center at external venues on numerous occasions. 
The directors collaborated with each other previously, are personal friends, and exhibit high levels of cognitive and affective trust towards each other. They share in the responsibility of creating and communicating the vision of the Center, together managing cognitive trust within the organization and with external stakeholders. This helps to alleviate common burnout, which often leads to a degradation of management's ability to create and maintain a Center's vision, vibrant research program and perceptions of cognitive trust.

To further broaden participation and trust in Center management, the directors are assisted by a management team that includes a site coordinator for each participating university, a coordinator of collaborative efforts, a higher education outreach coordinator, a kindergarten through 12th grade (K-12) education outreach coordinator, a technical program committee and an office manager. Site coordinators handle location-specific administrative issues, ranging from reserving a videoconference room for weekly meetings to distributing allocated budget funds. The coordinator of collaborative efforts manages socio-technical activities to support collaboration within the Center and coordinates social science research done in the Center. The higher education and K-12 outreach coordinators oversee the educational outreach activities done by Center members and their staff. The technical program committee (consisting of a lead scientist from each location and the Center's Director, Co-director and Deputy Director) provides input regarding natural science research and development.

The participation of representatives from each physical location provides ongoing dialog about challenges, progress, perceptions and ways of working at each location, important for building and maintaining cognitive trust. It facilitates learning about different ways of working and collaborative problem solving when members from different locations suggest how practices at their location may solve problems at other locations. For example, one team member suggested a possible solution to a colleague at a different location:

Another thing you can do... to magnify your undergraduate help is that you can have undergraduates getting paid for a certain amount of their research but then getting credit for a certain amount, so that you only have to pay for part of it... We pay[our undergraduate students], but... we also want them to take two semesters of [research credits].

Similarly, the participation of K-12 outreach, social science, minority and technical program coordinators on the management team facilitated coordination and collaboration, helping to manage cognitive trust, among these diverse domains.

Scientists and students in the Center have a primary affiliation with a university at which they are physically located. They became members by proposing and being asked to propose research projects and activities that would help the Center achieve its vision, mission and goals. The process included a preliminary proposal in which faculty were requested to provide a title and a brief statement of research objectives (six to eight lines in length). The technical program committee provided feedback to the faculty on their preliminary proposals. The preliminary proposals were:

A mechanism for earlier dialogue... The benefits are...to attempt to avoid excess overlap [between projects]; ...to identify opportunities for collaboration...not only within a given university, but also between universities; ... to identify any unmet needs. 
The proposals were reviewed and discussed by members of the Center's management team. Primary criteria used to evaluate the proposals included: fit to strategic plan, potential impact and scientific merit. Secondary criteria included: collaboration plan, K-12 outreach record and plan, and outside funds attracted. It is interesting to note that a detailed work plan is not requested, however, a collaboration plan is requested. Membership is based on high cognitive trust.

\section{Power}

Boulding (1990) describes three types of organizational power: destructive, economic and integrative. Destructive power, the power to destroy things, can be used as a prelude to production, where things are destroyed or altered to make way for production, and for carrying out a threat. An example of destructive organizational power is the firing of employees who are seen as resisting change in an organization. Economic power is used in all organizations. It involves the creation and acquisition of economic goods, including intellectual property, through production, exchange, taxation or theft. Integrative power involves the capacity to build organizations, inspire loyalty, to bind people together and to develop legitimacy. It has a productive and destructive aspect. In a negative sense it can create enemies and alienate people. All organizations have some integrative power or they could not survive. Some, however, rely on integrative power more than others; these include religious organizations, political movements, volunteer organizations and clubs. Their existence and growth are influenced by the extent to which the objectives of these organizations match the dynamic value structures within a larger population.

The conceptual organization appears to use a combination of integrative, economic and destructive power, however, their primary source of power appears to be integrative. They solicit funding and participation based on their vision, mission and goals. They attract funding from corporations, government agencies and other institutions by convincing them that their vision, mission and goals are valid and achievable. They can not promise an economic return on investment although they offer some hope to funding corporations that they will effectively educate students who may become future employees and generate patents and other knowledge that may have economic value. Conceptual organizations attract scientists and students similarly, i.e., they attract scientists and students by convincing them that the organization's vision, mission and goals are exciting and can provide great personal satisfaction. It assumes and requires cognitive and limited affective distrust.

The Center in this case study used integrative power in developing their vision, mission and goals. This was also a mechanism to increase cognitive trust. For example, when describing the process of developing a vision, the deputy director commented:

It's intended to be an inclusive process. We've included most of the [faculty] here in the Center in this process. Certainly our external advisory board had a part to play. It's iterative... We made our first draft of the vision, mission and goals, and reviewed those with [the faculty]... We then reviewed those with [industrial partners] and with our external advisory board. We got their input, what they thought we should be doing in a strategic direction...we integrated these comments.

The Center augmented integrative power with economic power in that they provide some funding to scientists and students. For example, in the Center scientists typically receive one month's summer salary, funding for one graduate student or $50 \%$ funding for a postdoctoral 
fellow, up to $\$ 4,000.00$ for supplies, and $\$ 500$ for travel. ${ }^{1}$ However, these amounts are by themselves not necessarily sufficient to build economic-based trust, i.e., to attract and retain high-caliber scientists who often receive government and corporate funding in much larger amounts. A vision that scientists are willing to support is also required. Cognitive trust facilitates belief in the vision.

As in any organization, destructive power is used when members do not meet expectations or keep commitments, i.e., when cognitive distrust emerges. This was manifest in the Center through decisions not to continue funding several scientists whose work was judged not in alignment with the Center's vision, mission and goals. For example, during a meeting deciding funding, participants supported and criticized proposals using comments such as:

This [proposed project] was not the lowest on my list, but I really miss the connection to objectives, goals, mission, etc. here. I could not see where this is going to lead.

These decisions, however, were reached through integrative power and were based on cognitive trust among the technical program committee members. The review was done collaboratively with the technical program committee, consisting of a lead scientist from each location and the Center's Director, Co-director and Deputy Director.

Thus, through interaction with faculty and collaboration among management team members, cognitive trust and distrust were enacted through integrative and destructive powers.

\section{Information and Communications Technology}

Because a conceptual organization is geographically distributed, it must utilize information and communications technology (I\&CT) as a mechanism to realize its vision and mission, or incur expensive monetary and temporal travel costs. In the Center studied, this has meant using traditional information and communications technology, such as the telephone, fax, mail and email, in ways typical of other R\&D organizations and scientific disciplines (e.g., Daft \& Lengel, 1984). It has also meant using newer technologies, such as video conferencing and web pages, in innovative ways to support the organization's vision, facilitate collaboration, and manage cognitive and affective trust and distrust.

Video conferencing is used for center-wide meetings and weekly research meetings. Center-wide meetings are held relatively infrequently (e.g., once every 6-8 months); these meetings included all members at all universities and have been used to share information among all Center members. For example, a center-wide meeting was held that introduced the Center's mission, organizational structure and center-wide activities several months after the Center was established. Research meetings are held weekly; all Center members are invited to attend these meetings, however, students are required to attend. Each meeting typically lasts one and one-half to two hours, and includes 20 to 30 Center members. During this time, students and postdoctoral fellows present and discuss their work.

\footnotetext{
${ }^{1}$ During the initial start-up year, funding for purchases of specialized scientific equipment was also provided on an as-needed basis.
} 
The format and technology used in these meetings have evolved over time. New social protocols to compensate for constraints imposed by the technology, and operations protocols to help reduce technical problems were developed and implemented working with Center members and technical staff (Sonnenwald, et al, 2002). Today these meetings increase members' awareness of one another's work and progress towards the vision, and, ideally, positively influencing cognitive trust.

One drawback to these meetings was their formal nature, negatively impacting affective trust. Students commented that the introduction of video conferencing, a large audience and PowerPoint ${ }^{\mathrm{TM}}$ slides meant they needed to spend more time to prepare their presentations. They felt their presentations had to be as formal as if they were presenting at a conference, and this formality made them hesitant to discuss work in progress and challenges they were facing. Several things have contributed to reducing the formality and increase the interactive nature of these meetings. First, faculty encouraged students to view their presentations as learning opportunities. Second, the directors and key students introduced informal aspects into their presentations, e.g., they used the drawing features of the electronic board to modify their slides in real time. Third, a new practice of having non-work communication before a presentation was initiated. In particular, the facilitator of each meeting asks each presenter several questions about their favorite activities and how they came to be at the Center. Interpersonal communication has also been shown to increase affective trust among distributed team members (Rocco, Finholt, Hofer, \& Herbsleb, 2000) and facilitate collaboration (Sonnenwald, 1996), a byproduct of cognitive trust.

Small group project meetings are held on an as needed basis among scientists and students who are collaborating on a project. These meetings were typically held face-to-face and/or via audioconferencing. Technology is currently being installed to provide video-conferencing and shared electronic whiteboards for small group project meetings. It will be interesting to investigate the impact of the technology on cognitive and affective trust.

Face-to-face interaction is traditionally recommended to augment interaction mediated by technology (e.g., Handy, 1995; Olson \& Olson, 2001; Rocco, et al, 2000), and Center members meet face-to-face at conferences held by professional organizations. They also occasionally visit members working at other locations, however, such travel is primarily limited to those working in the same state. This may limit the growth of affective trust.

A website was created to share Center news, expectations and resources among Center members and to communicate information about the Center to stakeholders. The content of the website is evolving and currently includes: the Center's vision statement, contact information, annual reports, call for proposals, virtual tours of lab facilities, Center meeting schedules, directory of Center members, personal web pages of Center members, a news bulletin that contains copies of press releases and announcements of awards and other recognition received by members, and forms to be used by members such as a confidentiality agreement. This type of content can help form a shared identity and affective trust across distances (Rocco, et al, 2000).

The website also contains pointers to resources that provide work, career and personal assistance to members, such as information about lab safety, suppliers, conferences, job interview process and apartment hunting services. This type of information supports a general anonymous mentoring function, allowing Center members (as well as the general public) to anonymously 
find information to assist in their careers and personal life. Thus these pages have the possibility of positively influencing feelings of cognitive and affective trust toward the Center.

Geographic distance can hinder the growth of cognitive and affective trust because it limits the opportunities to observe others' behavior, and observation mediated by I\&CT is limited by the technology's functionality. Innovative applications of the technology and changes in behavior appear necessary to help overcome these constraints and manage trust.

\section{EVERYDAY MANAGEMENT OF TRUST AND DISTRUST IN THE CONCEPTUAL ORGANIZATION}

Because the conceptual organization's vision and goals focus on complex and challenging problems, the organization will not meet its vision and goals without collaboration among its members. In this context, collaboration includes coordination but goes beyond coordination to include developing a shared understanding and shared creation of new knowledge. Cognitive trust is essential in the conceptual organization. Although the organizational structure, power and I\&CT within the conceptual organization help facilitate cognitive and affective trust, distrust can still arise. Following are two examples that illustrate cognitive distrust and affective distrust, and how the distrust was managed.

\section{Managing Cognitive Distrust in Conjunction with Affective Trust}

The following excerpt from a telephone meeting discussing research proposals submitted by Center members highlights the emergence of cognitive distrust and controls to monitor and support R\&D efforts of members who were the source of cognitive distrust. First, the problem is identified, and then a variety of solutions are discussed.

Person \#1: One of the critical areas for the Center as a whole is study related to [topic]...there is a lot of opportunity that's being missed between [the three scientists investigating this topic.] ...It's not a funding issue, it's really a matter of getting better coordination among at least three investigators and making sure that we've got the right communication and mentoring, etc., going on.

Person \#2: I really like the idea of every couple of months having a group meeting on this topic...

Person \#3: We could mandate and allocate these group meetings early on in the funding cycle ... to coordinate goals at that meeting... and come up with a written game plan...

Person \#4: I agree we don't want to go back and tell them that they have to write another proposal and we'll decide when we see that proposal whether they'll get funded or not...

Person \#1: One proposal would be that we ask the three of them to lead the meeting and open it up to others to go, to contribute. I think there are a few other people I'd like to have there. We could have [A] be the one to write the summary. And you know darn well, if [B's] in the room and it's got to be a collective document, [B] will contribute and it will be good...

Person \#3: I agree ... that that's a great idea. But it needs to go further...Make them produce a document tomorrow and then they go their separate ways. What they need to do is meet regularly as a group and listen to each other.... 
Person \#1: let me capture this...mandate a coordination meeting up-front, early in the funding cycle...so there's a [meeting] product which is a research game plan; ask them for dates of subsequent coordination meetings... and we could then state that this area is missing critical force with good opportunities, and encourage them to encourage their students and post-docs to be more collaborative.

The meeting participants question the competence and reliability of the three scientists as a group; the group is missing research opportunities. However, they do not question the scientists' motivation, attitudes or interpersonal interaction. In this situation, cognitive distrust exists simultaneously with affective trust.

The final proposed solution consists of mentoring and bringing additional expertise into the group. Thus controls to monitor and support efforts are established, and efforts to reduce the risk of critical work not being done are initiated (see Table 1).

\section{Managing Affective Distrust in Conjunction with Cognitive Trust}

Affective distrust can emerge between individuals when a person's actions appear to be personally harmful to others. Following is an excerpt from a telephone meeting in which a person's (Person \#2) motivations and activities regarding research in a particular topic area are questioned because they appear to overlap with the career interests and works of others (Person \#1 and Person \#3).

Person \#1: These sorts of Center activities I'm finding are more and more like a marriage. You really have to work at it to get things to work well. And everyone is certainly committed to try to make everything work as well as possible and so it's in that context and approach that I just want to address a topic that has that has come up... at our... [most recent] group meeting there was several of us in the audience and several of the students as well that were pretty surprised at the topics covered in [a student's] talk... it was surprising in the sense that we never heard about any of your intentions to do work on [a specific topic]..[It was not mentioned in] any of the plans that were submitted within the planned activities with the [Center]... [At] all the different management meetings that people participated in where a lot of ...work [in this topic area] was presented, it certainly appeared that [people from your location were] just silent on [this topic area.]

Person \#2: Well, a couple things. First, which management meeting are you referring to? Because...I'm really interested in seeing how we can be as helpful to the Center as possible. That's number one. And...it's important for me to be aware of what's going on and to coordinate with what's going on and I certainly want to do that ...I think you guys... met July $27^{\text {th }}$... The problem is that I was on vacation... that whole week. I'm really sorry I didn't I didn't call... I just missed it.

Person \#1: Well,...some of it was discussed in the [July] meeting, but certainly we've had group meetings where [a student working in this area] has presented his work. And you know we've been talking about [work on these topics] at national meetings.

Person \#2: I think [your student] talked to [my student] in some detail about these things [at the national meeting] because [my student] actually had a poster on this[at the national meeting]. 
Person \#3: Well I may need to talk to [my student] again but he was very surprised at the material that was presented [at the recent group meeting]. But I will ask him if he did talk to [your student] or not.

In the above exchange, the response to issues regarding motivation and activities is formal in nature. Person \#2 mentions specific meeting dates and interactions. These events are invoked to clarify his motivation and justify activities. He continues, providing information about the history of the project and explicitly stating his motivations and intentions.

Person \#2: I should probably tell you about the history of the project... to make sure that we're not doing the same thing you're doing. The impression I had was that you had an interest in looking at [a specific subtopic] and we're not doing any of that... [Gives example of previous work he and his students did on related subtopics] so you know we've got a long history of looking at that... I'm going to be very, very careful here. I don't want to step on people's toes.

Person \#1: I appreciate that, and that's why we're all talking through this.

Person \#2: The reason I want to join the Center is I want to help the Center. I want to collaborate. I want to do things that complement what you're doing and it just wouldn't make sense for me to just go do something that one of you guys said you want to do.

Person \#3: We all agree on that. That's why we're talking this out.

In the exchange above, the value of collaboration and cooperation are acknowledged, and the discussion shifts slightly to include how things could be done differently to avoid these types of problems.

Person \#1: We need to encourage the students at these group meetings to be even more interactive. I remember [the student's talk] ... and you know if there were folks that were down the road with some information related to this it certainly would have been more beneficial to engage [the student] in a discussion and present some related data... And that's something we probably could encourage more of our students to do more of....

Person \#2: Absolutely....

At this point in the meeting, a discussion about how video-conferencing technology may have limited information dissemination and exchange among students, and how students forget to copy their advisors when exchanging information via e-mail ensued. Future activities focusing on sharing data and equipment are also discussed. These activities will help monitor and constrain activities. Affective distrust regarding work plans still exists however as evidenced in the following exchange.

Person \#1: Beyond the details of the science,...we need to be very specific and accountable regarding our projection of plans. You know we're really going to be challenged going 
forward with the [Center] about strategic planning and coordination of activities...For example there's nothing in the in the annual report we turned in a month or two ago that says anything about the work that [your student has] worked on.

Person \#2: Well, you see I went and looked at that annual report and [this topic area] is unbelievably sketchy...I think this happens throughout the Center;...in terms of future plans... there's almost nothing.

Person \#1: We need to be a little more clear...but there's nothing in [your sections] related to this on accomplishments or future plans...

As previously, the response to challenges regarding intentions is formal in nature. Person $\# 2$ cites formal documentation as a justification for his actions. Subsequently he states the work will not continue, although in doing so places some blame on the student as well as re-iterate that his intentions and motivations are not to harm but help.

Person \#2: So really [my student] doesn't plan to stay focused on this. His plan, and the other thing too, is that as his advisor I kind of feel like I have limited, I can suggest things, but it was sort of his idea...

Person \#1: I understand you, we can't control where the students' curiosity takes them. That often gets me in trouble with companies when it looks like I've influenced the direction and I've tried to stay out of the way and the kid naturally goes there. That sort of things happen all the time and we don't want to do anything to inhibit that.

Person \#2: And I tried really hard to look through and read the [Center's] documentation so that I know what everybody is doing...I really had the impression your interest was [something else.]...The goal of the Center has got to be synergism. It's got to be helping each other.

Person \#3: I agree.

Person \#1: Well I think everyone agrees these are good conversations and healthy to continue to build the trust among all the [Center members] and I thank everyone for participating.

Although the work relationship and collaboration among the meeting participants will continue, some affective distrust lingered as evidenced by the following conversation that occurred among Person \#1 and 4 (who also participated in the meeting) immediately following.

Person \#1: You sort of get a sense that [Person \#2] was prepared for this discussion. because he looked up [the Center documentation] and knew about the plans and said it was shoddy... I'm still perplexed by that one phone call that hung up [earlier in the meeting.] ... I think it's clearly on his radar to be more sensitive to it. I'm sort of curious about what led him to be prepared, and I imagine my emails certainly would have led to that discussion, especially if he were sensitive to the issue. 
Person \#1: Regarding his visit with my lab, I will hand select the people he'll speak with and it will be the topics that are obvious within the Center

...

Person \#4: Yeah, just a comment...Everything we've heard is that he's trying to be on the up and up, and maybe he was just at the borderline and so I don't think we need to treat him like he can't be trusted.

Person \#1: I agree.

Person \#4: So long as we have the ground rules straight and make sure that we all are clear on where he's going with it and be able to collaborate.

In this situation, no evidence of cognitive distrust emerged. That is, no one questioned anyone's research competence or research quality. In general, two groups of scientists working on the same topic is usually not an issue for most group members if the competence of the other group is thought to be inferior.

Although cognitive distrust did not exist, affective distrust did. It was managed through a discussion that identified issues and perceptions. Specific data was presented and good will was expressed to counter perceptions. Solutions included changes in work plans and information and equipment sharing were agreed to. Competitive collaboration is occurring. Affective distrust was reduced or accommodated but did not disappear.

\section{COLLABORATION DATA AS EVIDENCE OF TRUST}

As illustrated in Table 1, collaboration can be viewed as a byproduct, or indirect measure, of cognitive trust or affective trust. To investigate collaboration within the Center, two sociometric surveys were conducted. As mentioned earlier each survey asked Center members to identify other Center members they were currently collaborating with. The first survey took place one year after the Center was established; the second took place two years after the Center was established.

Table 2. Reported Collaborations in the Center

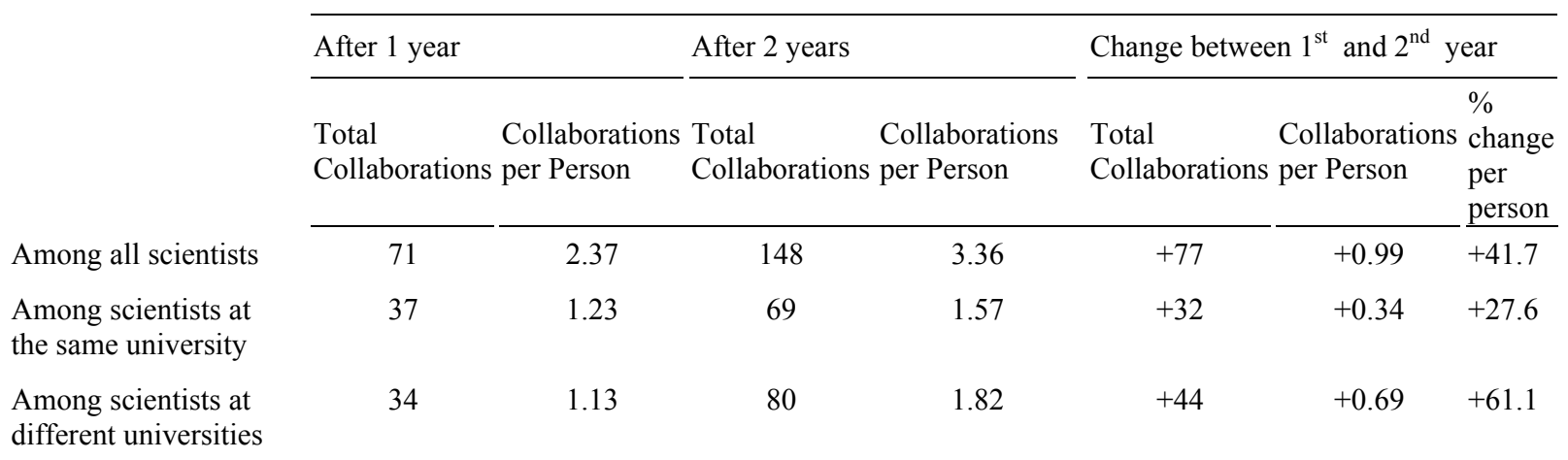


The number of collaborations reported among faculty scientists increased from an average of 2.37 per scientist to 3.36 per scientist; a $41.7 \%$ increase (see Table 2). A larger increase was seen in the growth of collaborations among scientists at different universities than among scientists at the same university (61.1\% versus $27.6 \%)$. This indicates that collaboration among scientists within the organization has developed across universities (and distances). It suggests that the organizational structure, power and use of I\&CT within the conceptual organization have facilitated, or at least not impeded, the formation and maintenance of trust.

\section{CONCLUSION}

Trust management is important in any organization, but especially important in conceptual organizations and other organizations that are geographically distributed and knowledge-based. In particular, when organizations need to address large complex and challenging problems of national and global importance, and collaboration among the best scientists and experts irrespective of discipline, department or institution affiliation is required, cognitive and affective trust are both necessary to create a shared understanding and new knowledge.

Typical trust mechanisms, such as informal face-to-face interactions and observations, to build and maintain trust are not inherently present in these organizations. Infrastructure that explicitly supports the creation and maintenance of trust appears to be vital. The infrastructure in R\&D organizations, including academic institutions, is typically based on department and disciplinary boundaries with intense competition for resources, authority and territory (Benowitz, 1995; Salter \& Hearn, 1996). The empirical case study data presented in this chapter illustrates that participation in management by representatives at each physical location, early and continuing dialog between organization members and management, and use of integrative power are three infrastructure mechanisms to manage cognitive trust.

Information and communications technology is a necessity in any geographically distributed organization today, and yet it can limit the creation and maintenance of cognitive and affective trust. However, the case study data suggest innovative use of I\&CT, such as interactive videoconferencing, interactive shared application software, and websites that share organizational information and news, in conjunction with changes in behavior may help overcome the inherent limitations of I\&CT with respect to trust.

Tightly-coupled collaboration appears to only emerge in situations where high cognitive and affective trust simultaneously exist. No collaboration will emerge in situations with high cognitive and affective distrust exist. As the case study data illustrates, limited collaboration emerges when affective trust and cognitive distrust exist concurrently. Non-critical work tasks may be given to individuals in these situations, and controls to monitor and support task completion may be utilized. In comparison, competitive collaboration emerges when cognitive trust and affective distrust exist concurrently. Controls to constrain work activities may emerge to manage affective distrust. Limited and competitive collaboration may be manageable but neither situation is ideal. As one participant noted, when these situations occur "collaboration isn't fun." 
Additional longitudinal data and data from other organizations is needed to increase our understanding of trust within the conceptual organization and similar types of organizations. Issues to investigate include the sustainability of trust over time across distances, and longerterm consequences of distrust.

\section{Acknowledgements.}

This chapter is based upon work supported by the STC Program of the National Science Foundation under Agreement No. CHE-9876674. I would like to thank Noriko Hara, Reto Bolliger and Marcus Donie for assistance in sociometric data collection, and the R\&D Center management team and Center members for their generous participation in this research, and the anonymous reviewers and editors for their comments.

\section{REFERENCES}

Adler, P. \& Adler, P. (1987). Membership Roles in Research. Newbury Park, CA: Sage.

Benowitz, S. (1995). Wave of the future: Interdisciplinary collaboration. The Scientist, 9(13), 1,4 .

Boulding, K. (1989). The Three Faces of Power. Newbury Park, CA: Sage.

Daft, R.L., \& Lengel, R.H. (1984). Information richness: a new approach to managerial behavior and organizational design. In L.L. Cummings \& B.M. Shaw (Eds.), Research in Organizational Behavior (pp. 191-233). Greenwich, CT: JAI Press.

Duarte, D., \& Snyder, N. (1999). Mastering Virtual Teams. San Francisco: Jossey-Bass Publishers.

Handy, C. (1995). Trust and the virtual organization. Harvard Business Review, May-June, 4350 .

Jarvenpaa, S., \& Leidner, D. (1999). Communication and trust in global virtual teams. Organization Science, 10(6), 791-815.

Jones, G., \& George, J. (1998). The experience and evolution of trust: Implications for cooperation and teamwork. Academy of Management Review, 23(3), 531-546.

Kanter, R. (1994). Collaborative advantage: The art of alliances. Harvard Business Review, 72(4), 96-109.

Lewicki, R., McAllister, D., \& Bies, R. (1998). Trust and distrust: New relationships and realities. Academy of Management Review, 23(3), 438-458.

McAllister, D. (1995). Affect- and cognition-based trust as foundations for interpersonal cooperation in organizations. Academy of Management Journal, 38(1), 24-59.

McKnight, D., Cummings, L., \& Chervany, N. (1998). Initial trust formation in new organizational relationships. Academy of Management Review, 23(3), 479-490.

Olson, G.M., \& Olson, J.S. (2000). Distance matters. Human-Computer Interaction, 15(2-3), 139-178.

Orlikowski, W. (1993), Learning from Notes: Organizational issues in groupware implementation. The Information Society, 9(3), 237-250.

Robson, C. (2002). Real World Research. Oxford, UK: Blackwell.

Rocco, E., Finholt, T., Hofer, E., \& Herbsleb, J. (2001). Out of sight, short of trust. Presentation at the Founding Conference of the European Academy of Management, Barcelona, Spain.

Rocco, E., Finholt, T., Hofer, E., Herbsleb, J. (2000). Designing as if trust mattered. CREW Technical Report, University of Michigan. 
Rousseau, D., Sitkin, S., Burt, R., \& Camerer, C. (1998). Not so different after all: A crossdiscipline view of trust. Academy of Management Review, 23(3), 393-404.

Salter, L., \& Hearn, A. (1996). Outside the lines. Montreal, Canada: McGill-Queen's University.

Sonnenwald, D.H., Solomon, P., Hara, N., Bolliger, R., \& Cox, T. (2002). Collaboration in the large: Using video conferencing to facilitate large group interaction. A. Gunasekaran, $\mathrm{O}$. Khalil and S. Rahman (Eds.) Knowledge and Information Technology in $21^{\text {st }}$ Century Organizations: Human and Social Perspectives (pp. 115-136). Hershey, PA: Idea Group Publishing.

Sonnenwald, D.H. (1996). Communication roles that support collaboration during the design process. Design Studies, 17, 277-301.

Sztompka, P. (1999). Trust: A Sociological Theory. Cambridge, UK: University Press.

Wasserman, S., \& Faust, K. (1994). Social Network Analysis. NY: Cambridge University Press.

Whitener, E., Bridt, S., Korsgaard, M., \& Werner, J. (1998). Managers as initiators of trust: An exchange relationship framework for understanding managerial trustworthy behavior. Academy of Management Review, 23(3), 513-530. 